\title{
Comparison of injuries to New Zealand rock lobsters (Jasus edwardsii) caused by hand versus snare collection
}

\author{
WARRICK POWRIE \\ GRANT W. TEMPERO* \\ Centre for Biodiversity and Ecology Research \\ Department of Biological Sciences \\ School of Science and Engineering \\ The University of Waikato \\ Private Bag 3105 \\ Hamilton 3240, New Zealand \\ *Author for correspondence: gwt2@waikato.ac.nz
}

\begin{abstract}
Following the prohibition in New Zealand of lobster snares in late 2005, we undertook research to compare the frequency and extent of injuries to rock lobsters (Jasus edwardsii) (Hutton) caused by recreational SCUBA divers using lobster snares compared with hand collection. Rock lobsters were sampled between January 2006 and October 2006 from multiple dive sites around the North Island of New Zealand. Of the 124 rock lobsters caught, $20.9 \%$ were in a soft shell state. Female rock lobsters constituted $43.5 \%$ of the catch, but only one was carrying eggs. Female mean tail width was $72.2 \mathrm{~mm}$; male mean tail width was $71.9 \mathrm{~mm}$. We found that hand collection caused significantly more injuries than snare collection, to both soft shell and hard shell animals. Hand collection also resulted in more major injuries, with $18 \%$ of hard shell animals and $31 \%$ of soft shell animals losing two or more limbs. We recommend that the prohibition on the use of rock lobster snares be lifted, as their use appears to significantly reduce injury and stress to rock lobsters in recreational dive areas, and increase the survival of undersized individuals released after capture.
\end{abstract}

Keywords autotomy; crayfish; lassos; red rock lobster; spiny lobster

Z09001; Online publication date 27 March 2009 Received 7 January 2009; accepted 16 February 2009

\section{INTRODUCTION}

The New Zealand spiny or rock lobster (Jasus edwardsii) (Hutton) is found throughout coastal waters of southern Australia and New Zealand, including the Chatham Islands, to a maximum recorded depth of $275 \mathrm{~m}$ (Annala \& Bycroft 1984). Rock lobsters are an important commercial and recreational species in both Australia and New Zealand (Starr et al. 2003). Based on a national survey, an estimated 534000 rock lobsters were taken by New Zealand recreational fishers in 1996 (Bradford 1998).

Autotomy and autospasy are widespread in the decapod Crustacea (Wood \& Wood 1932). While there is little published work, New Zealand rock lobsters do appear to be capable of autospasy, if not autotomy of their pereiopods and antennae to escape from predators and to limit wounds. However, the ecological and physiological effects of limb loss on this species are currently unknown.

Studies conducted on other crustacean species have shown that loss of antenna or limbs have significant adverse effects on the growth, behaviour and ecology of these species. Negative effects on the exploratory behaviour of individual crayfish (Cherax destructor), from which one antenna had been lost or removed, subsequently disadvantaged the animal in new environments and in conflict situations (Koch et al. 2006). Experiments have also demonstrated that limb injury reduces growth, foraging efficiency and mating success while increasing vulnerability to attack (Juanes \& Smith 1995). Increased mortality was observed in the rock lobster (Jasus lalandii) from the west coast of South Africa in response to the loss of three or more appendages (Brouwer et al. 2006). This research suggests that the loss of multiple appendages during capture would have an adverse effect on any animals subsequently returned to the environment.

Until 2005, New Zealand rock lobsters could be caught by non-commercial divers either by hand or with a short "loop" or "snare" to remove 
rock lobsters from their refuges. In late 2005, New Zealand government legislation was introduced prohibiting the use of rock lobster snares, despite the fact that no studies had been conducted on the effects of snares on rock lobsters.

The purpose of this study was to assess (1) the number of injuries sustained by rock lobsters during hand or snare collection by recreational divers and (2) whether being in a hard shell or a soft shell (i.e., post moulting) state affected the number of injuries sustained.

\section{MATERIALS AND METHODS}

Collection of rock lobsters was undertaken by several recreational divers under a Ministry of Fisheries special permit (307), Auckland University of Technology (client number 9791209). Collection methods used included manual snares supplied by Prodive New Zealand, and hand collection. The snare consisted of a long hollow stainless steel tube approximately $1.2 \mathrm{~m}$ in length and $0.8 \mathrm{~cm}$ in diameter with a $0.6 \mathrm{~cm}$ stainless steel wire threaded through the tube forming a loop at one end and attached to a solid handle at the other end. The handle is used to manually draw the loop closed, ensnaring the rock lobster. During collection the snare is pulled closed and inserted into the crevice behind the rock lobster. Once in position the snare is opened and pulled forward over the rock lobster's tail, and then drawn closed, ensnaring the animal. Once snared, the rock lobster tends to move forward releasing any grip it may have on the rock and allowing itself to be extracted from the hole. Spring loaded models were not employed.

For every dive, each SCUBA diver was supplied with a snare and two catch bags, one for rock lobsters captured by hand and one for those captured with a snare. Dive times were evenly split between collections by hand and collections by snare, but it was not logistically possible to collect equal numbers of animals caught by the two techniques. Once the dive was completed, each catch bag was brought to the surface where the lobsters were sexed. All animals were measured to the nearest millimetre across the second calcified bar on the tail.

Shell state was defined as soft or hard (soft shells permit movement of the carapace that can be seen when a little force is applied). Any undersize, in berry or soft shell lobsters were recorded, and then returned to the water within $3 \mathrm{~min}$ of exposure, to prevent damage to the eyes from ultraviolet light. Each rock lobster was examined for injury, and the number of appendages lost and any recent damage to the carapace was recorded. Pre-existing injuries were identified from the presence of necrotic or regenerated tissue. The loss of a pereiopod, an antenna, or damage to the horns or carapace, were each counted as a single injury, e.g., a lobster missing a leg and an antenna and with damage to a horn, was recorded as sustaining three injuries.

Data were tested for normality with a Shapiro Wilks W test. All other statistical tests were conducted according Dytham (2003). All analyses were conducted using Statistica (StatSoft Inc. 2008).

\section{RESULTS}

Between January 2006 and October 2006 we collected a total of 124 rock lobsters (Table 1), of which 70 $(56.5 \%)$ were male and $54(43.5 \%)$ female. Only three of the 26 rock lobsters $(20.9 \%$ of total catch) classed as in the soft shell state were males $(2.4 \%)$ and only one female was in berry. Female mean tail width was $72.6 \mathrm{~mm}( \pm 11.6 \mathrm{SD})$; male mean tail width was $72.8 \mathrm{~mm}( \pm 15.3 \mathrm{SD})$. Mean tail width for hand caught rock lobsters was $73.0 \mathrm{~mm}( \pm 13.8 \mathrm{SD})$; snare caught rock lobsters had a mean tail width of $72.1 \mathrm{~mm}( \pm 13.8 \mathrm{SD})$. No pre-existing injuries were found on any of the rock lobsters sampled.

Among 41 snare caught rock lobsters, only 3 injuries were recorded, compared to 113 injuries from

Table 1 Numbers of New Zealand rock lobster (Jasus edwardsii) collected by hand and by snare by recreational SCUBA divers.

\begin{tabular}{lcccr}
\hline Method of collection & Soft carapace & Hard carapace & Male & Female \\
\hline Hand & 16 & & 0 & 16 \\
Snare & 10 & 67 & 3 & 7 \\
Hand & & 31 & 43 & 24 \\
Snare & & 24 & 7 \\
\hline
\end{tabular}


Fig. 1 Number of injuries sustained by individual New Zealand rock lobsters (Jasus edwardsii) caught by hand or by snare.
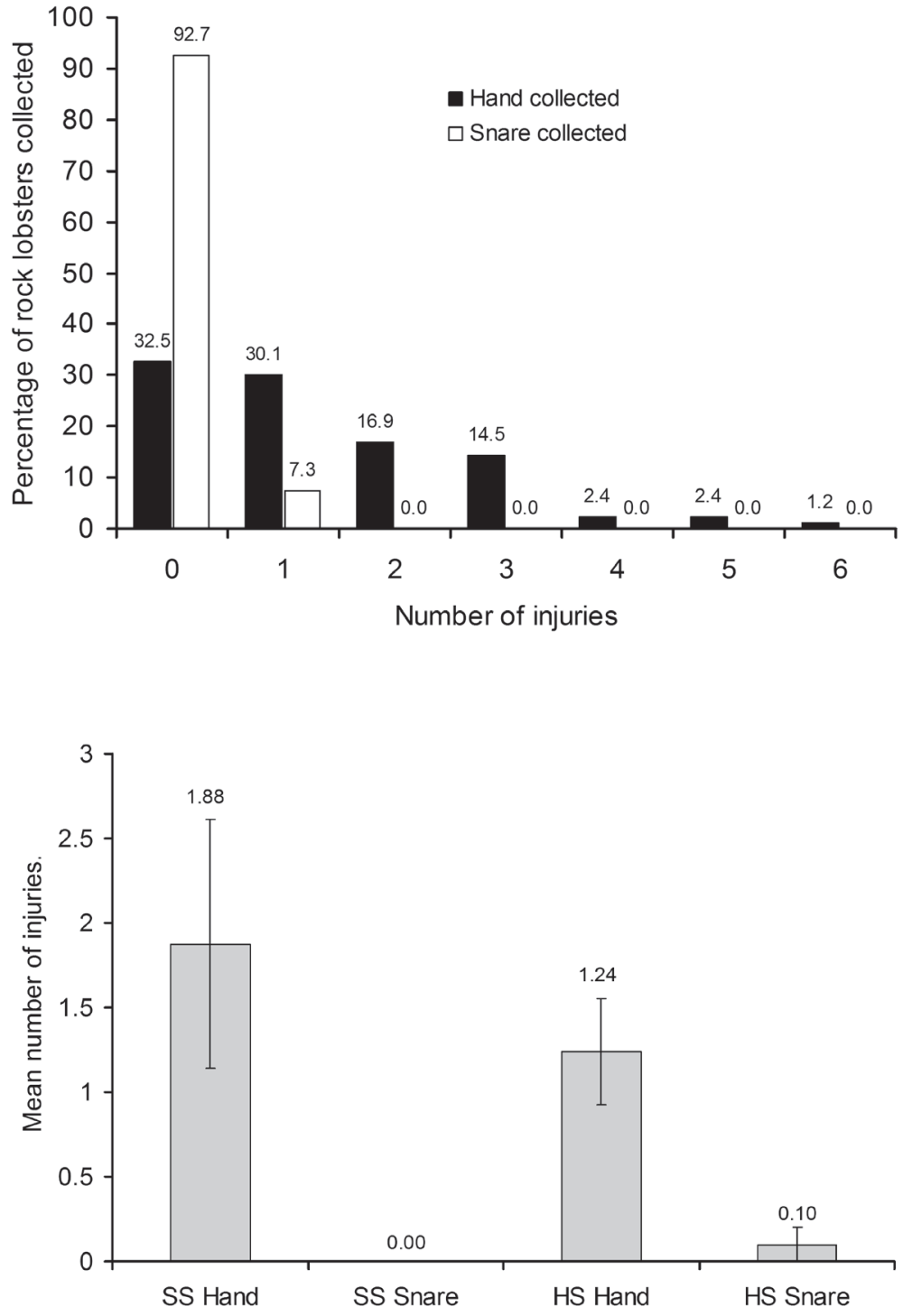

Fig. 2 Mean number of injuries ( $\pm 95 \% \mathrm{CI}$ ) sustained by soft shell (SS) and hard shell (HS) New Zealand rock lobsters (Jasus edwardsii) caught by hand or by snare. the 83 hand caught animals. Multiple injuries were comparatively common $(>33.3 \%)$ in hand caught animals, while only one snare caught animal had a second injury, the loss of a single antenna (Fig. 1).

There were insufficient data to test for significant differences in the number of injuries between hand caught and snare caught soft shell rock lobsters. A student's $t$-test revealed a significant difference $(t$ $=4.76$, d.f. $=96, P<0.05)$ in the number of injuries between hand caught and snare caught, hard shell rock lobster; hand caught rock lobsters sustained significantly more injuries (Fig. 2). Statistical tests also found that injuries were as common among soft shell as hard shell animals caught by hand ( $t$-test, $t=$ 1.69 , d.f. $=81, P>0.05)$, and as common among soft shell and hard shell animals caught in snares ( $t$-test, $t=1.01$, d.f. $=39, P>0.05$ ). The number of injuries did not vary with gender $(t$-test, $t=1.2$, d.f. $=122$, $P>0.05$ ) or body size (Spearman rank correlation, $r=0.05, n=124, P>0.05)$.

Hand collection caused more major injuries than did snare collection: $18 \%$ of hard shell animals 

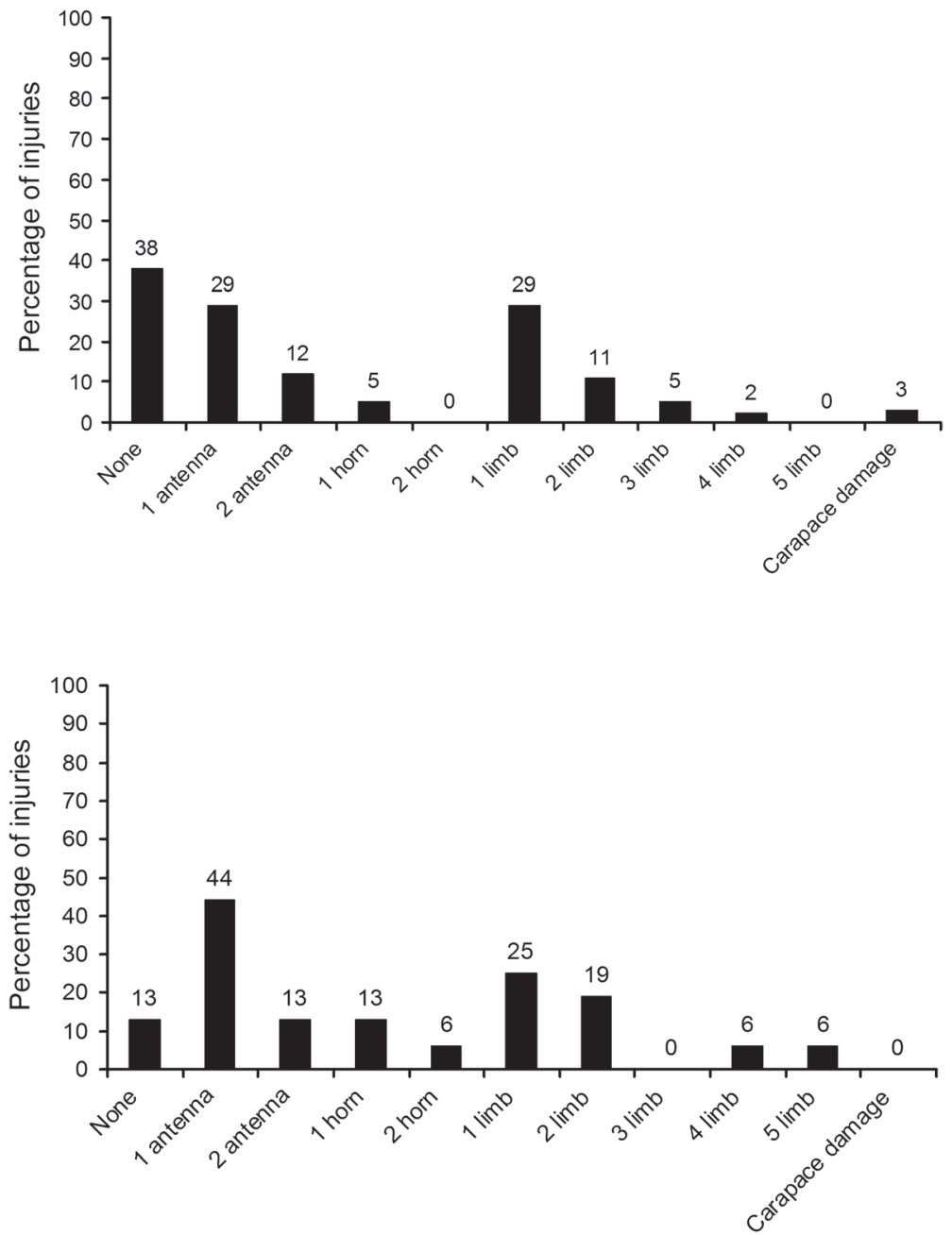

Fig. 3 Damage caused by hand collection of hard shell New Zealand rock lobsters (Jasus edwardsii) $(n=67)$. Percentage of injuries: counts of cases in which a body structure was lost or the carapace was damaged.

Fig. 4 Damage caused by hand collection of soft shell New Zealand rock lobster (Jasus edwardsii) $(n=16)$. Percentage of injuries: counts of cases in which a body structure was lost or the carapace was damaged.
(Fig. 3) and 31\% of soft shell animals (Fig. 4) lost two or more limbs; $57 \%$ of soft shell and $41 \%$ of hard shell rock lobsters lost one or more antennae; one or more horns on $19 \%$ of soft shell and $5 \%$ of hard shell rock lobsters were lost or damaged during hand collection.

\section{DISCUSSION}

While injury levels to decapod crustacean species from commercial operations such as trawling (Bergman et al. 2001) and traps (Brouwer et al. 2006) have been documented, comparatively few studies have been published on levels of injury caused by recreational SCUBA divers. A pre- and post-harvest season visual survey of injuries sustained by spiny lobster (Panulirus argus) from recreational SCUBA divers was conducted by Parsons \& Eggleston (2005). They found that the number of injured spiny lobsters increased by $27 \%$ after the harvest season in some locations. However, no studies have been conducted on injuries to rock lobsters in relation to method of collection by recreational SCUBA divers.

We found a higher frequency of injuries to appendages and carapaces of New Zealand rock lobsters collected by hand, both hard shell and soft shell animals, than in those caught by snares. In addition, hand caught lobsters were more likely to suffer the loss of multiple appendages, while snare caught animals suffered comparatively minor injuries. Although only a small number of soft shell rock lobsters were collected by snare, they suffered no injuries during collection. 
These results clearly suggest that collection of rock lobsters by the use of manual snares reduces the likelihood of significant injury to the animal. Legislation prohibiting the use of snares was justified on the grounds that snares were classed as rock lobster pots and therefore did not have the required escape aperture for undersized animals. However, the logic behind this is flawed, because hand-collected individuals are visually targeted, and the collector can recognise most undersized individuals before attempting a catch. We did not collect sufficient data to decide whether the soft shell condition increases the risk of injury, but our observations suggest that soft shelled rock lobsters are at least at no greater risk of injury in a snare than are those caught by hand.

Undersized rock lobsters collected by either method are required to be released. No long-term survival data of caught and released soft shell and hard shell animals are available, but our preliminary findings suggest that changes in the legislation allowing for the use of rock lobster snares would benefit the rock lobster fishery by reducing incidental injury and mortality during collection by recreational fishers. Further investigation of this difference should be considered as an area of research importance.

\section{ACKNOWLEDGMENTS}

We gratefully acknowledge the support of Prodive and the New Zealand Recreational Fishing Council of New Zealand. We also thank Ian Duggan and the two anonymous reviewers for their comments and suggestions on this manuscript.

\section{REFERENCES}

Annala JH, Bycroft BL 1984. Exploratory fishing for rock lobsters in offshore areas near Gisborne. Fisheries Research Division Occasional Publication 45.

Bergmann M, Beare DJ, Moore PG 2001. Damage sustained by epibenthic invertebrates discarded in the Nephrops fishery of the Clyde Sea area, Scotland. Journal of Sea Research 45: 105-118.

Bradford E 1998. Harvest estimates from the 1996 national marine recreational surveys. New Zealand Fisheries Assessment Research Document 98/16.

Brouwer SL, Groeneveld JC, Blows B 2006. The effects of appendage loss on growth of South African west coast rock lobster, Jasus lalandii. Fisheries Research 78: 236-242.

Dytham C 2003. Choosing and using statistics. 2nd ed. Melbourne, Australia, Blackwell Publishing.

Juanes F, Smith LD 1995. The ecological consequences of limb damage and loss in decapod crustaceans: a review and prospectus. Journal of Experimental Marine Biology and Ecology 193: 197-223.

Koch LM, Patullo BW, MacMillian DL 2006. Exploring with damaged antennae: do crayfish compensate for injuries? Journal of Experimental Biology 209: 3226-3233.

Parsons DM, Eggleston DB 2005. Indirect effects of recreational fishing on behavior of the spiny lobster Panulirus argus. Marine Ecology-Progress Series 303: 235-244.

Starr PJ, Bentley N, Breen PA, Kim SW 2003. Assessment of red rock lobsters (Jasus edwardsii) in CRA 1 and CRA 2 in 2002. New Zealand Fisheries Assessment Report 2004/41. 119 p.

Wood FD, Wood HE 1932. Autotomy in decapod Crustacea. Journal of Experimental Zoology 62: 1-55. 